\title{
Analysis of Three Primary mtDNA Mutations in 155 Patients with Leber's Hereditary Optic Neuropathy
}

Yan-Jiao Yao ( $\nabla$ yaoyj001@126.com )

Fuzhou Second Hospital

\section{Xue-Mei Zhuang}

Fuzhou Second Hospital

\section{Fan Zheng}

Fuzhou Second Hospital

\section{Research}

Keywords: LHON, mtDNA mutations, G3460A, G11778A, T14484C, Chinese pedigrees

Posted Date: November 5th, 2020

DOI: https://doi.org/10.21203/rs.3.rs-101558/v1

License: (c) (i) This work is licensed under a Creative Commons Attribution 4.0 International License. Read Full License 


\section{Abstract}

Background: Leber's Hereditary Optic Neuropathy (LHON) is a maternal inherited disease caused by mitochondrial DNA (mtDNA) mutations. The aim of the current study is to analysis the frequencies of mitochondrial ND1 G3460A, ND4 G11778A and ND6 T14484C mutations in patients with LHON.

Methods: Our study enrolled 155 patients with LHON and 83 controls, PCR-Sanger sequencing was performed to screen the presence of these primary mutations. Moreover, we performed clinical, genetic and molecular characterizations of five Chinese families carrying LHON-related three primary mutations.

Results: 28 patients with G3460A (18.1\%), 86 patients with G11778A (55.5\%) and 32 patients carrying T14484C mutation $(20.6 \%)$ were identified. However, none of these primary mutations were identified in controls. Among them, one patient carrying G3460A, two patients with G11778A and two patients with T14484C mutation had an obvious family history of LHON. Clinical evaluation of these pedigrees showed the variable clinical phenotypes with different age at onset of LHON. Sequence analysis of the complete mtDNA genes from the matrilineal relatives suggested the presence of these primary mutations. However, the lack of any functional variants in mtDNA genes revealed that mitochondrial haplogroups or haplotypes may not play important roles in the clinical phenotypic manifestation of LHON-associated primary mutations.

Conclusions: Our data indicated that screening for the mtDNA primary mutations was necessary for early detection, prevention and diagnosis of LHON.

\section{Background}

LHON was a common maternally inherited disease caused by mtDNA mutations, which led to subacute optic atrophy resulting in severe visual impairment in most affected persons [1]. Several documented LHON cases had involved abnormal symptoms, including movement disorders, dystonia or multiple-sclerosis-like symptoms, which remains a big challenge for clinicians [2,3]. To date, the molecular mechanism underlying LHON was still not fully understood. Since the landmark discovery of the LHONassociated mtDNA ND4 G11778A mutation [4], more than 30 LHON-related mtDNA mutations had been reported among various ethnic population [5]. Notably, three primary mtDNA mutations: ND1 G3460A, ND4 G11778A and ND6 T14484C, which involved genes encoding the subunits of respiratory chain complex I, accounted for $>90 \%$ of LHON pedigrees in some countries [6, 7]. Moreover, LHON mutations were predominantly homoplasmic with incomplete penetrance and marked male bias concerning clinical affection [8], suggesting that additional factors may influence the conversion to symptomatic LHON, like mtDNA genetic background, nuclear genes and environmental factors.

With the aim of exploring the molecular basis for LHON, we recently initiated a mutational screening for the three primary mtDNA mutations in a cohort of $155 \mathrm{LHON}$ patients and 83 healthy subjects. Moreover, we performed clinical, genetic and molecular analysis of five Han Chinese families with LHON-associated mtDNA primary mutations.

\section{Materials And Methods}

\section{Subjects and ethics statement}

155 patients (99 males and 56 females, aged from 4 to 33 years, with an average of 18 years) received ophthalmological examinations at Fuzhou Second Hospital, affiliated to Xiamen University, were categorized according to the expression of LHON clinical features, such as painless, acute or subacute vision loss. Moreover, a total of 83 control subjects (41 males and 42 females, aged from 8 to 24 years, with an average of 13 years) were obtained from the Physical Examination Center of our hospital. The written informed consents conforming to the tenets of the Declaration of Helsinki were obtained from each participant prior to the study. The institutional review boards of Fuzhou Second Hospital, Xiamen University approved this study.

\section{Screening for three primary mtDNA mutations}


For DNA extraction, $5 \mathrm{~mL}$ of peripheral blood was collected by cubital vene-punction from each person (155 LHON patients and 83 controls) enrolled in the study. Following extraction procedure, DNA was quantified and checked for quality by UV spectrophotometry. To screen the LHON-associated primary mtDNA mutations, we carried out the PCR-Sanger sequencing to detect the ND1 G3460A, ND4 G11778A and ND6 T14484C mutations. The affected individuals' DNA fragments spanning these mtDNA mutations were amplified by PCR using oligodeoxynucleotides corresponding to mtDNA at positions 3108-3717 for the ND1 G3460A mutation, 11654-11865 for the ND4 G11778A mutation, and 14260-14510 for the ND6 T14484C mutation [9-12]. The sequences of primers for detecting the ND1 G3460A mutation were: forward: 5'-ATGAAGAATAGGGCGAAGGG-3', reverse: 5'TACTTCACAAAGCGCCTTCC-3'; the primers sequences for screening the ND4 G11778A mutation were: forward: 5'-

GGAGAATGGGGGATAGGTGT-3', reverse: 5'- TCACTCTCACTGCCCAAGAA-3', while the primers sequences for screening the ND6 T14484C mutation were: forward: 5'-AGAATATTGAGGCGCCATTG-3', reverse: 5'- GCATAATTAAACTTTACTTC-3'. PCR products were purified and sequenced by Big Dye Terminator chemistry using the Applied Biosystems 3700 automated sequencer (Applied Biosystems). Then the sequence data was compared with the revised Cambridge Reference sequence (rCRS, GenBank accession no. NC_012920.1) [13].

\section{Clinical and molecular features of five LHON pedigrees with three primarymutations}

Five Chinese pedigrees, as shown in Figure 2, were ascertained in the Department of Ophthalmology, Fuzhou Second Hospital, Xiamen University. Members of these pedigrees were interviewed at length to identify both personal or family medical histories of visual impairments, and other clinical abnormalities. The ophthalmic examinations of the probands and other matrilineal relatives, including visual field test, visual acuity examination, fundus photography, visual evoked potentials and determination of the degree of visual impairment, as well as other clinical evaluations, were conducted as described previously [14]. The degree of visual loss was classified based on the following criteria: healthy, $\geq 0.3$, mild, 0.1 to 0.299; moderate, 0.05 to 0.099 ; severe, 0.02 to 0.049 ; and profound, $<0.02$.

The complete mitochondrial genomes of the affected LHON individuals (FZ010: II-1 and III-8; FZ011: II-6 and III-2; FZ012: III-1 and III-4; FZ013: III-14 and IV-6; FZ014: III-5) were PCR amplified by using 24 primers, as described in a previous study [15]. Each fragment was purified and subsequently was analyzed by direct sequencing in an ABI 3700 automated DNA sequencer using the Big Dye Terminator Cycle sequencing reaction kit (Applied Biosystems). These sequence results were compared with the rCRS (GenBank accession number: NC_012920.1) to detect the mutations/variants [13].

\section{Phylogenetic analysis}

The mtDNA sequences of 15 different vertebrates were used to conduct an inter-specific analysis as reported previously [16]. The conservation index $(\mathrm{Cl})$ of each mtDNA mutation was calculated, we regarded the $\mathrm{Cl} \geq 75 \%$ as having functional potential [17].

\section{Haplogroup analysis}

The entire mtDNA sequences of the five Chinese pedigrees carrying the mtDNA primary mutations were assigned to the Asian mitochondrial haplogroups by using the nomenclature of mitochondrial haplogroups [18].

\section{Results}

\section{Mutational screening of LHON-associated three primary mutations}

The study samples with LHON consisted of 99 males and 56 females. All participants were Han Chinese subjects recruited from Department of Ophthalmology, Fuzhou Second Hospital, Xiamen University in China. After PCR-Sanger sequencing, we identified 28 patients with G3460A mutation (18.1\%), 86 patients with G11778A mutation (55.5\%) and 32 patients carrying T14484C mutation (20.6\%) (Fig. 1). But we failed to detect these primary mutations in 83 healthy controls.

\section{Clinical characterization of five Han Chinese families with mtDNA primary mutations}


In our case-control study for genetic screening of LHON-related three primary mtDNA mutations, five Han Chinese families, as shown in Fig. 2, were ascertained in Fuzhou Second Hospital, Xiamen University. In family FZ010, the proband (II-1) was 31year-old man who lived in Fuzhou City of Fujian Province. The comprehensive history interview indicated that he did not have any other clinical abnormalities such as diabetes, cardiovascular disease, deafness, cancer or neurological disorders. In addition, he began to suffer from painless and progressive bilateral vision loss (right eye: 0.01 and left eye: 0.03 ) at the age of 18 , he observed a dark cloud in the center of his vision and had difficulty discerning colors, which all appeared dark grey. Moreover, the family member (III-8) had vision failure (right eye: 0.1 and left eye: 0.2 ).

In family FZ011, the proband (III-2) complained of painless, progressive deterioration of bilateral vision impairment at the age of 4 and went to the Eye Center of Fuzhou Second Hospital, Xiamen University. His visual acuity was 0.08 and 0.04 at the right and left. Ophthalmological and other clinical evaluations showed that he had a typical clinical feature of LHON. In addition, the matrilineal relative (II-6) was also LHON carrier.

In family FZ012, the proband (III-1) began suffering from painless, progressive deterioration of bilateral vision impairment at the age of 11 years old and came to Ophthalmology Clinic at the Fuzhou Second Hospital, Xiamen University. She saw a dark cloud in the center of vision and had problems appreciating colors that all seemed dark gray. Her visual acuity was 0.01 and 0.03 at the right and left. Among other matrilineal relatives, the subject (III-4) experienced loss of vision at the age of 12 , visual acuity of III- 4 was 0.1 in both eyes.

In family FZ013, the proband (III-14) was diagnosed with LHON at the age of 25 by the Ophthalmology Clinic at Fuzhou Second Hospital, Xiamen University. His visual acuity was 0.2 in both eyes. Among other members in this pedigree, the subject (IV-6) was LHON carrier, and her visual acuity was 0.03 in both eyes. However, other members in this family were normal vision.

In family FZ014, the proband (III-5) came to the Eye Center of Fuzhou Second Hospital, Xiamen University at the age of 12, he suffered painless, progressive deterioration of visual impairment at the age of 12 . He saw a dark cloud in the center of vision and had problems appreciating colors that all seemed a dark gray, and his visual acuity was 0.1 in both eyes. However, none of other members in this family had any vision deficit. The clinical features of several members from these pedigrees were listed in Table 1.

Table 1

Summary of the clinical and molecular data for nine patients carrying LHON-associated three primary mtDNA mutations

\begin{tabular}{|lllllllll|}
\hline $\begin{array}{l}\text { Pedigree } \\
\text { number }\end{array}$ & Subject & Sex & $\begin{array}{l}\text { Age at } \\
\text { test } \\
\text { (year) }\end{array}$ & $\begin{array}{l}\text { Age at } \\
\text { onset } \\
\text { (year) }\end{array}$ & $\begin{array}{l}\text { Primary } \\
\text { mtDNA } \\
\text { mutation }\end{array}$ & $\begin{array}{l}\text { Visual } \\
\text { acuity } \\
\text { (Right) }\end{array}$ & $\begin{array}{l}\text { Visual } \\
\text { acuity } \\
\text { (Left) }\end{array}$ & $\begin{array}{l}\text { Level of visual } \\
\text { impairment }\end{array}$ \\
\hline FZ010 & II-1 & Male & 31 & 18 & G3460A & 0.01 & 0.03 & Severe \\
\hline FZ010 & III-8 & Male & 5 & 5 & G3460A & 0.1 & 0.2 & Mild \\
\hline FZ011 & II-6 & Female & 21 & 15 & G11778A & 0.2 & 0.1 & Mild \\
\hline FZ011 & III-2 & Male & 4 & 4 & G11778A & 0.08 & 0.04 & Severe \\
\hline FZ012 & III-1 & Female & 15 & 11 & G11778A & 0.01 & 0.03 & Profound \\
\hline FZ012 & III-4 & Male & 12 & 12 & G11778A & 0.1 & 0.1 & Mild \\
\hline FZ013 & III-14 & Male & 25 & 20 & T14484C & 0.2 & 0.2 & Mild \\
\hline FZ013 & IV-6 & Female & 7 & 6 & T14484C & 0.03 & 0.03 & Severe \\
\hline FZ014 & III-5 & Male & 12 & 12 & T14484C & 0.1 & 0.1 & Mild \\
\hline
\end{tabular}


To explore the molecular basis for LHON, we performed the mutational screening for the mtDNA variants in these matrilineal relatives (FZ010: II-1 and III-8; FZ011: II-6 and III-2; FZ012: III-1 and III-4; FZ013: III-14 and IV-6; FZ014: III-5), as well as the healthy subjects. We first amplified the complete mitochondrial genomes of these LHON patients by using 24 primers as previously described [14], the PCR products were purified and subsequently analyzed in an ABI 3700 automated DNA sequencer using the Big Dye Terminator Cycle sequencing reaction kit. Sequences were handled by the DNASTAR program (DNAS Inc, Madison, USA). Compared with the rCRS, matrilineal relatives of these families revealed sets of genetic variations belonging to different mitochondrial haplogroup F1a, D5b1, F1, M7b1, M10a, respectively [18] (Table 2). Among them, there were 22 variants in D-loop, 4 variants in 12S rRNA and 3 variants in 16S rRNA, one common 9-bp deletion in the conjunction between tRNA ${ }^{\text {Lys }}$ and $\mathrm{CO} 2$ gene, while other variants were found in mitochondrial protein-coding genes. Furthermore, 20 missense mutations were found, including the ND1 G3316A (Ala to Thr), G3460A (Ala to Thr) and G4048A (Asp to Asn), ND2 C5178A (Leu to Met), ATP8 C8414T (Leu to Phe) and A8498G (Lys to Glu), ATP6 G8584A (Ala to Thr), A8701G (Thr to Ala), A8860G (Thr to Ala) and C9071T (Ser to Leu), ND3 A10398G (Thr to Ala), ND4 G11778A (Arg to His), ND5 A12361G (Thr to Ala), A13681G (Thr to Ala) and G13708A (Ala to Thr), ND6 T14484C (Met to Val), CytB C14766T (Thr to lle), C14883T (Thr to Ile), A15236G (lle to Val) and A15326G (Thr to Ala). In addition, evolutionary conservation analysis was performed for these variants between 15 species, including mouse [19], bovine [20] and Xenopus laevis [21]. However, besides the ND4 G11778A mutation, other mutations/variants were well conserved. 
Table 2

mtDNA sequence variants in five LHON families

\begin{tabular}{|c|c|c|c|c|c|c|c|c|c|c|}
\hline Gene & Position & Replacement & $\begin{array}{l}\text { Conservation } \\
(\mathrm{H} / \mathrm{B} / \mathrm{M} / \mathrm{X})^{\mathrm{a}}\end{array}$ & rCRS $^{b}$ & FZ010 & FZ011 & FZ012 & FZ013 & FZ014 & $\begin{array}{l}\text { Previously } \\
\text { reported }^{c}\end{array}$ \\
\hline \multirow{22}{*}{$\begin{array}{l}\text { D- } \\
\text { loop }\end{array}$} & 73 & A to $G$ & & $A$ & $\mathrm{G}$ & G & G & G & G & Yes \\
\hline & 143 & $\mathrm{G}$ to $\mathrm{A}$ & & $\mathrm{G}$ & & $A$ & & $A$ & $A$ & Yes \\
\hline & 146 & $\mathrm{~T}$ to $\mathrm{C}$ & & $\mathrm{T}$ & $\mathrm{C}$ & & & & C & Yes \\
\hline & 150 & $\mathrm{C}$ to $\mathrm{T}$ & & C & $\mathrm{T}$ & $\mathrm{T}$ & $\mathrm{T}$ & $\mathrm{T}$ & $\mathrm{T}$ & Yes \\
\hline & 152 & $\mathrm{~T}$ to $\mathrm{C}$ & & $\mathrm{T}$ & & C & & $\mathrm{C}$ & & Yes \\
\hline & 185 & $\mathrm{G}$ to $\mathrm{A}$ & & G & & A & $A$ & & & Yes \\
\hline & 195 & $\mathrm{~T}$ to $\mathrm{C}$ & & $\mathrm{T}$ & $\mathrm{C}$ & & & $\mathrm{C}$ & $\mathrm{C}$ & Yes \\
\hline & 207 & $\mathrm{G}$ to $\mathrm{A}$ & & $\mathrm{G}$ & $A$ & & & & & Yes \\
\hline & 263 & A to $G$ & & $A$ & G & G & & & G & Yes \\
\hline & 310 & $\mathrm{~T}$ to $\mathrm{TC} / \mathrm{CTC}$ & & $\mathrm{T}$ & $\mathrm{TC}$ & СTC & СТC & $\mathrm{TC}$ & СТC & Yes \\
\hline & 489 & $\mathrm{~T}$ to $\mathrm{C}$ & & $\mathrm{T}$ & $\mathrm{C}$ & C & $\mathrm{C}$ & $\mathrm{C}$ & $\mathrm{C}$ & Yes \\
\hline & 515 & Del A & & $A$ & & Del A & & & & Yes \\
\hline & 568 & $\mathrm{C}$ to $\mathrm{CCCC}$ & & C & & & & CCCC & & Yes \\
\hline & 16066 & A to $G$ & & $A$ & $\mathrm{G}$ & & G & & G & Yes \\
\hline & 16163 & A to $G$ & & $A$ & & G & & $\mathrm{G}$ & & Yes \\
\hline & 16172 & $\mathrm{~T}$ to $\mathrm{C}$ & & $\mathrm{T}$ & & C & & & C & Yes \\
\hline & 16189 & $\mathrm{~T}$ to $\mathrm{C}$ & & $\mathrm{T}$ & & C & C & & C & Yes \\
\hline & 16223 & $\mathrm{C}$ to $\mathrm{T}$ & & C & $\mathrm{T}$ & & $\mathrm{T}$ & & & Yes \\
\hline & 16266 & $\mathrm{C}$ to $\mathrm{T}$ & & $\mathrm{C}$ & & $\mathrm{T}$ & & & $\mathrm{T}$ & Yes \\
\hline & 16319 & $G$ to $A$ & & G & $A$ & & A & $A$ & & Yes \\
\hline & 16360 & $\mathrm{C}$ to $\mathrm{T}$ & & C & & $\mathrm{T}$ & & $\mathrm{T}$ & & Yes \\
\hline & 16519 & $\mathrm{~T}$ to $\mathrm{C}$ & & $\mathrm{T}$ & & & C & & $C$ & Yes \\
\hline \multirow{4}{*}{$\begin{array}{l}12 S \\
\text { rRNA }\end{array}$} & 709 & $G$ to $A$ & $\mathrm{G} / \mathrm{A} / \mathrm{A} / \mathrm{A}$ & G & A & & A & & A & Yes \\
\hline & 750 & A to $G$ & $\mathrm{~A} / \mathrm{A} / \mathrm{A} / \mathrm{G}$ & $A$ & G & G & G & G & G & Yes \\
\hline & 1438 & A to $G$ & $\mathrm{~A} / \mathrm{A} / \mathrm{A} / \mathrm{G}$ & $A$ & G & G & G & G & G & Yes \\
\hline & 1598 & $G$ to $A$ & $\mathrm{G} / \mathrm{A} / \mathrm{T} / \mathrm{A}$ & $\mathrm{G}$ & $A$ & & & $A$ & & Yes \\
\hline $\begin{array}{l}\text { 16S } \\
\text { rRNA }\end{array}$ & 2120 & $\mathrm{G}$ to $\mathrm{A}$ & $\mathrm{G} / \mathrm{A} / \mathrm{T} / \mathrm{T}$ & G & & A & & & $A$ & Yes \\
\hline \multicolumn{11}{|c|}{$\begin{array}{l}\text { aConservation of amino acids in polypeptides or nucleotides in RNA in humans }(\mathrm{H}) \text {, bovine (B), mouse (M) and Xenopus } \\
\text { laevis }(\mathrm{X})\end{array}$} \\
\hline \multicolumn{11}{|c|}{${ }^{b}$ rCRS: reversed Cambridge Reference Sequence } \\
\hline
\end{tabular}




\begin{tabular}{|c|c|c|c|c|c|c|c|c|c|c|}
\hline Gene & Position & Replacement & $\begin{array}{l}\text { Conservation } \\
(\mathrm{H} / \mathrm{B} / \mathrm{M} / \mathrm{X})^{\mathrm{a}}\end{array}$ & rCRS $^{b}$ & FZ010 & FZ011 & FZ012 & FZ013 & FZ014 & $\begin{array}{l}\text { Previously } \\
\text { reported }^{c}\end{array}$ \\
\hline & 2706 & A to $G$ & $\mathrm{~A} / \mathrm{G} / \mathrm{A} / \mathrm{A}$ & $A$ & G & G & G & G & & Yes \\
\hline & 3010 & $\mathrm{G}$ to $\mathrm{A}$ & $\mathrm{G} / \mathrm{G} / \mathrm{A} / \mathrm{A}$ & G & & $A$ & $A$ & & $A$ & Yes \\
\hline \multirow[t]{6}{*}{ ND1 } & 3316 & $\begin{array}{l}\text { G to A (Ala } \\
\text { to Thr) }\end{array}$ & $A / I / I / I$ & G & $A$ & & & & $A$ & Yes \\
\hline & 3460 & $\begin{array}{l}\text { G to A (Ala } \\
\text { to Thr) }\end{array}$ & $\mathrm{A} / \mathrm{A} / \mathrm{A} / \mathrm{G}$ & G & $A$ & & & & & Yes \\
\hline & 3606 & A to $G$ & & & G & & G & & G & Yes \\
\hline & 3970 & $\mathrm{C}$ to $\mathrm{T}$ & & C & $\mathrm{T}$ & $\mathrm{T}$ & & $\mathrm{T}$ & $\mathrm{T}$ & Yes \\
\hline & 4048 & $\begin{array}{l}\text { G to A (Asp } \\
\text { to Asn) }\end{array}$ & $\mathrm{D} / \mathrm{N} / \mathrm{Y} / \mathrm{F}$ & G & & $A$ & $A$ & & & Yes \\
\hline & 4086 & $\mathrm{C}$ to $\mathrm{T}$ & & C & & $\mathrm{T}$ & $\mathrm{T}$ & & & Yes \\
\hline \multirow[t]{5}{*}{ ND2 } & 4715 & A to $G$ & & $A$ & & G & & G & & Yes \\
\hline & 4769 & A to $G$ & & $A$ & G & G & G & G & G & Yes \\
\hline & 4883 & $\mathrm{C}$ to $\mathrm{T}$ & & C & $\mathrm{T}$ & $\mathrm{T}$ & $\mathrm{T}$ & $\mathrm{T}$ & $\mathrm{T}$ & Yes \\
\hline & 5178 & $\begin{array}{l}\text { C to A (Leu } \\
\text { to Met) }\end{array}$ & $\mathrm{L} / \mathrm{T} / \mathrm{T} / \mathrm{T}$ & C & & A & & & $A$ & Yes \\
\hline & 5301 & A to $G$ & & $A$ & & G & & G & & Yes \\
\hline \multirow[t]{4}{*}{ C01 } & 5978 & A to $G$ & & $A$ & & G & G & & & Yes \\
\hline & 6026 & $\mathrm{G}$ to $\mathrm{A}$ & & G & & & & & $A$ & Yes \\
\hline & 7028 & $\mathrm{C}$ to $\mathrm{T}$ & & C & $\mathrm{T}$ & $\mathrm{T}$ & $\mathrm{T}$ & $\mathrm{T}$ & $\mathrm{T}$ & Yes \\
\hline & 7196 & $C$ to $A$ & & C & & $A$ & & & $A$ & Yes \\
\hline NC7 & $\begin{array}{l}8271- \\
8279\end{array}$ & Del 9-bp & & 9-bp & & & $\begin{array}{l}\text { Del 9- } \\
\text { bp }\end{array}$ & $\begin{array}{l}\text { Del 9- } \\
\text { bp }\end{array}$ & & Yes \\
\hline \multirow[t]{2}{*}{ ATP8 } & 8414 & $\begin{array}{l}\text { C to T (Leu } \\
\text { to Phe) }\end{array}$ & $\mathrm{F} / \mathrm{M} / \mathrm{L} / \mathrm{W}$ & C & $\mathrm{T}$ & $\mathrm{T}$ & $\mathrm{T}$ & $\mathrm{T}$ & $\mathrm{T}$ & Yes \\
\hline & 8498 & $\begin{array}{l}\text { A to G (Lys } \\
\text { to Glu) }\end{array}$ & $\mathrm{K} / \mathrm{L} / \mathrm{M} / \mathrm{S}$ & $A$ & & & & G & & Yes \\
\hline \multirow[t]{4}{*}{ ATP6 } & 8584 & $\begin{array}{l}\text { G to A (Ala } \\
\text { to Thr) }\end{array}$ & $\mathrm{A} / \mathrm{V} / \mathrm{V} / \mathrm{T}$ & G & $A$ & & $A$ & & $A$ & Yes \\
\hline & 8701 & $\begin{array}{l}\text { A to } G(T h r \\
\text { to Ala) }\end{array}$ & $\mathrm{T} / \mathrm{S} / \mathrm{L} / \mathrm{Q}$ & $A$ & G & G & G & G & G & Yes \\
\hline & 8860 & $\begin{array}{l}\text { A to } G \text { (Thr } \\
\text { to Ala) }\end{array}$ & $\mathrm{T} / \mathrm{A} / \mathrm{A} / \mathrm{T}$ & $A$ & G & G & G & G & G & Yes \\
\hline & 9071 & $\begin{array}{l}\text { C to } \mathrm{T} \text { (Ser to } \\
\text { Leu) }\end{array}$ & $\mathrm{S} / \mathrm{M} / \mathrm{M} / \mathrm{L}$ & C & & $\mathrm{T}$ & & & $\mathrm{T}$ & Yes \\
\hline
\end{tabular}

${ }^{a}$ Conservation of amino acids in polypeptides or nucleotides in RNA in humans (H), bovine (B), mouse (M) and Xenopus laevis $(\mathrm{X})$

brCRS: reversed Cambridge Reference Sequence

${ }^{c}$ As presented in online mitochondrial genome databases: www.mitomap.org and www.genpat.uu.se/mtDB. 


\begin{tabular}{|c|c|c|c|c|c|c|c|c|c|c|}
\hline Gene & Position & Replacement & $\begin{array}{l}\text { Conservation } \\
(\mathrm{H} / \mathrm{B} / \mathrm{M} / \mathrm{X})^{\mathrm{a}}\end{array}$ & $\mathrm{rCRS}^{\mathrm{b}}$ & FZ010 & FZ011 & FZ012 & FZ013 & FZ014 & $\begin{array}{l}\text { Previously } \\
\text { reported }^{c}\end{array}$ \\
\hline \multirow[t]{2}{*}{$\mathrm{CO} 3$} & 9540 & $\mathrm{~T}$ to $\mathrm{C}$ & & $\mathrm{T}$ & C & C & $\mathrm{C}$ & $\mathrm{C}$ & & Yes \\
\hline & 9950 & $\mathrm{~T}$ to $\mathrm{C}$ & & $\mathrm{T}$ & C & & & & C & Yes \\
\hline \multirow[t]{2}{*}{ ND3 } & 10398 & $\begin{array}{l}\text { A to G (Thr } \\
\text { to Ala) }\end{array}$ & $\mathrm{T} / \mathrm{T} / \mathrm{T} / \mathrm{A}$ & $A$ & & G & & G & G & Yes \\
\hline & 10400 & $\mathrm{C}$ to $\mathrm{T}$ & & C & $\mathrm{T}$ & & & $\mathrm{T}$ & $\mathrm{T}$ & Yes \\
\hline \multirow[t]{3}{*}{ ND4 } & 10873 & $\mathrm{~T}$ to $\mathrm{C}$ & & $\mathrm{T}$ & $\mathrm{C}$ & C & $\mathrm{C}$ & C & $\mathrm{C}$ & Yes \\
\hline & 11719 & $G$ to $A$ & & $\mathrm{G}$ & & $A$ & & & $A$ & Yes \\
\hline & 11778 & $\begin{array}{l}\text { G to A (Arg } \\
\text { to His) }\end{array}$ & $\mathrm{R} / \mathrm{R} / \mathrm{R} / \mathrm{R}$ & G & & $A$ & $A$ & & & Yes \\
\hline \multirow[t]{5}{*}{ ND5 } & 12705 & $\mathrm{C}$ to $\mathrm{T}$ & & $\mathrm{C}$ & $\mathrm{T}$ & $\mathrm{T}$ & $\mathrm{T}$ & $\mathrm{T}$ & $\mathrm{T}$ & Yes \\
\hline & 12361 & $\begin{array}{l}\text { A to } G \text { (Thr } \\
\text { to Ala) }\end{array}$ & $\mathrm{T} / \mathrm{L} / \mathrm{L} / \mathrm{L}$ & $A$ & & & & G & G & Yes \\
\hline & 13104 & A to $G$ & & $A$ & & G & $\mathrm{G}$ & G & & Yes \\
\hline & 13681 & $\begin{array}{l}\text { A to G (Thr } \\
\text { to Ala) }\end{array}$ & $\mathrm{T} / \mathrm{L} / \mathrm{D} / \mathrm{T}$ & $A$ & G & & & & G & Yes \\
\hline & 13708 & $\begin{array}{l}\text { G to A (Ala } \\
\text { to Thr) }\end{array}$ & $\mathrm{A} / \mathrm{T} / \mathrm{T} / \mathrm{I}$ & G & & $A$ & $A$ & $A$ & & Yes \\
\hline \multirow[t]{3}{*}{ ND6 } & 14484 & $\begin{array}{l}\text { T to C (Met } \\
\text { to Val) }\end{array}$ & $\mathrm{M} / \mathrm{M} / \mathrm{L} / \mathrm{L}$ & $\mathrm{T}$ & & & & C & $\mathrm{C}$ & Yes \\
\hline & 14569 & $\mathrm{G}$ to $\mathrm{A}$ & & G & $A$ & $A$ & $A$ & $A$ & $A$ & Yes \\
\hline & 14668 & $\mathrm{C}$ to $\mathrm{T}$ & & C & $\mathrm{T}$ & $\mathrm{T}$ & $\mathrm{T}$ & $\mathrm{T}$ & $\mathrm{T}$ & Yes \\
\hline \multirow[t]{8}{*}{ CytB } & 14766 & $\begin{array}{l}\mathrm{C} \text { to } \mathrm{T} \text { (Thr } \\
\text { to lle) }\end{array}$ & $\mathrm{T} / \mathrm{S} / \mathrm{T} / \mathrm{S}$ & C & $\mathrm{T}$ & $\mathrm{T}$ & & $\mathrm{T}$ & $\mathrm{T}$ & Yes \\
\hline & 14783 & $\mathrm{~T}$ to $\mathrm{C}$ & & $\mathrm{T}$ & $C$ & C & C & $C$ & $C$ & Yes \\
\hline & 14883 & $\begin{array}{l}\text { C to T (Thr } \\
\text { to lle) }\end{array}$ & T/L/I/I & $\mathrm{C}$ & & $\mathrm{T}$ & & $\mathrm{T}$ & & Yes \\
\hline & 15043 & $\mathrm{G}$ to $\mathrm{A}$ & & G & A & A & $A$ & $A$ & A & Yes \\
\hline & 15236 & $\begin{array}{l}\text { A to } G \text { (lle to } \\
\text { Val) }\end{array}$ & $\mathrm{I} / \mathrm{I} / \mathrm{I} / \mathrm{S}$ & $A$ & & G & & & G & Yes \\
\hline & 15301 & $G$ to $A$ & & $\mathrm{G}$ & $A$ & $A$ & $A$ & $A$ & $A$ & Yes \\
\hline & 15326 & $\begin{array}{l}\text { A to } G(T h r \\
\text { to Ala) }\end{array}$ & $\mathrm{T} / \mathrm{M} / \mathrm{I} / \mathrm{I}$ & $A$ & G & G & $\mathrm{G}$ & G & G & Yes \\
\hline & 15784 & $\mathrm{~T}$ to $\mathrm{C}$ & & $\mathrm{T}$ & & & C & & $C$ & Yes \\
\hline \multicolumn{11}{|c|}{$\begin{array}{l}\text { aConservation of amino acids in polypeptides or nucleotides in RNA in humans }(\mathrm{H}) \text {, bovine (B), mouse (M) and Xenopus } \\
\text { laevis }(\mathrm{X})\end{array}$} \\
\hline \multicolumn{11}{|c|}{ brCRS: reversed Cambridge Reference Sequence } \\
\hline
\end{tabular}


Table 3

Summary of clinical and molecular data for 19 Chinese pedigrees carrying LHON-related three primary mutations

\begin{tabular}{|c|c|c|c|c|c|c|c|c|}
\hline Pedigree & $\begin{array}{l}\text { Ratio } \\
\text { (affected } \\
\text { male/female) }\end{array}$ & $\begin{array}{l}\text { Average } \\
\text { age of } \\
\text { onset } \\
\text { (years) }\end{array}$ & $\begin{array}{l}\text { Number of } \\
\text { matrilineal } \\
\text { relative }\end{array}$ & $\begin{array}{l}\text { Penetrance } \\
\text { (\%) }\end{array}$ & $\begin{array}{l}\text { mtDNA } \\
\text { primary } \\
\text { mutations }\end{array}$ & $\begin{array}{l}\text { mtDNA } \\
\text { haplogroup }\end{array}$ & $\begin{array}{l}\text { Secondary } \\
\text { Mutations }\end{array}$ & References \\
\hline FZ010 & $2: 0$ & 11.5 & 12 & 16.7 & G3460A & F1a1 & None & This study \\
\hline FZ011 & $1: 1$ & 9.5 & 8 & 25.0 & G11778A & D5b1 & None & This study \\
\hline FZ012 & $1: 1$ & 11.5 & 4 & 50.0 & G11778A & $\mathrm{F} 1$ & None & This study \\
\hline FZ013 & $1: 1$ & 13 & 9 & 22.2 & T14484C & M7b1 & None & This study \\
\hline FZ014 & $1: 0$ & 12 & 6 & 16.7 & T14484C & M10a & None & This study \\
\hline WZ33 & $1: 5$ & 28.7 & 21 & 28.6 & G3460A & A & None & 12 \\
\hline WZ34 & $0: 1$ & 19 & 14 & 7.1 & G3460A & M7b1 & None & 12 \\
\hline WZ35 & $2: 0$ & 23 & 6 & 33.3 & G3460A & M12 & None & 12 \\
\hline WZ36 & $1: 0$ & 26 & 7 & 14.3 & G3460A & M7c1 & None & 12 \\
\hline WZ41 & $1: 0$ & 18 & 7 & 14.3 & G11778A & M8a2 & None & 27 \\
\hline WZ42 & $2: 0$ & 14.5 & 25 & 8 & G11778A & D4g2 & None & 27 \\
\hline WZ43 & $1: 0$ & 15 & 9 & 11.1 & G11778A & B4a1c & None & 27 \\
\hline WZ2 & $3: 1$ & 14 & 14 & 57.1 & G11778A & D5 & $\begin{array}{l}\text { tRNA }{ }^{\mathrm{Met}} \\
\text { A4435G }\end{array}$ & 28 \\
\hline WZ3 & $2: 1$ & 19 & 10 & 60 & G11778A & D4 & $\begin{array}{l}\text { tRNA }{ }^{\text {Thr }} \\
\text { A15951G }\end{array}$ & 29 \\
\hline WZ18 & $0: 1$ & 25 & 17 & 5.9 & T14484C & D4 & None & 9 \\
\hline WZ19 & $1: 0$ & 24 & 13 & 7.7 & T14484C & $\mathrm{D} 4 \mathrm{~g} 1 \mathrm{~b}$ & None & 9 \\
\hline WZ20 & $1: 0$ & 6 & 9 & 11.1 & T14484C & R11 & None & 9 \\
\hline WZ21 & $1: 0$ & 17 & 6 & 16.7 & T14484C & $\mathrm{R} 11 \mathrm{a}$ & None & 9 \\
\hline WZ22 & $1: 0$ & 13 & 7 & 14.3 & T14484C & D4 & None & 9 \\
\hline
\end{tabular}

\section{Discussion}

In the present study, we analyzed the frequencies of three primary mtDNA mutations in a cohort of 155 patients with LHON and 83 control subjects. In fact, the ND1 G3460A, ND4 G11778A and ND6 T14484C mutations accounted for more than $90 \%$ of cases of LHON worldwide. The prevalence of each mutation varied among different populations, but the average was $69 \sim 92 \%$ for ND4 G11778A, and 3 19\% for ND6 T14484C and ND1 G3460A [22-26]. However, these mtDNA mutations were only responsible for $38.3 \%$ cases in a cohort of 903 Chinese Han families with LHON [2], indicating the variation in the incidence and spectrum of mtDNA mutations among the different ethnic backgrounds. Here, we showed that the incidence of the ND1 G3460A, ND4 G11778A and ND6 T14484C mutation was 18.1\%, 55.5\% and 20.6\%, respectively.

Clinical and genetic evaluations revealed the variable severity and age at onset in visual impairment in these matrilineal relatives, although these subjects shared some common features, specifically, the rapid, painless, bilateral loss of central vision. The average age at onset for visual impairment in matrilineal relatives in these families, as shown in Table 3, varied from 9.5 years (FZ011) to 13 years (FZ013). Moreover, a wide range of penetrance and expressivities of LHON was observed in these Chinese families, penetrances of optic neuropathy (affected matrilineal relatives/total matrilineal relatives) in these five 
Chinese families ranged from 16.7 to $50 \%$, with the average of $26.12 \%$. Furthermore, the average age-of-onset for optic neuropathy ranged from 6 to 28.7 years, with the average of 18.7 years in other 14 Chinese families $[9,12,27-28]$ (Table 3).

The relative low penetrances of LHON in these five families strongly indicated that the ND1 G3460A, ND4 G11778A and ND6 T14484C mutations were not sufficient to produce the clinical phenotypes, hence, other modified factors such as environmental factors, nuclear genes, mtDNA haplogroups and epigenetic modification may contribute to the clinical manifestation of LHON-associated mtDNA primary mutations $[29,30]$.

Recently, many studies reported that mtDNA background affected the expression of LHON. For example, in the European families, the risk of optic neuropathy increased when the ND4 G11778A and ND6 T14484C mutations were present in the haplogroup J [31, 32], and when the ND1 G3460A mutation occurred in the haplogroup K [32]. Furthermore, secondary LHON mutations such as ND1 T4216C and ND5 G13708A may increase the penetrance and expressivity of LHON associated with the primary ND4 G11778A and ND6 T14484C mutations [32]. In the Chinese families carrying the G11778A mutation, the haplogroup M7b1'2 significantly increased the risk of optic neuropathy, whereas the haplogroup M8a had a protective effect [33]. Moreover, the mitochondrial haplogroup M9a specific variant ND1 T3394C may modify the penetrance and expressivity of ND4 G11778A mutation [34]. In the present study, sequence analysis of the complete mitochondrial genomes of the matrilineal relatives of these five pedigrees revealed the presence of ND1 G3460A, ND4 T11778A and ND6 T14484C, as well as set of genetic polymorphisms belonging to human mitochondrial haplogroup F1a1, D5b1, F1, M7b1 and M10a [18] (Tables 2 and 3). Whereas the other 14 Chinese pedigrees carrying the ND1 G3460A or ND4 G11778A or ND6 T14484C mutation belong to haplogroup A, M7b1, M12, M7c1, M8a2, D4g2, B4a1c, D5, D4, D4g1b, R11 and R11a, respectively [18]. This suggested that the G3460A, G11778A and T14484C mutations occurred sporadically and multiplied through evolution of the mtDNA in China. However, there was the absence of secondary LHON mutations in these five Chinese families. By contrast, two Chinese families with higher penentrance of vision loss harbored functionally significant mtDNA variants: the tRNA ${ }^{\text {Met }} A 4435 G$, and tRNA ${ }^{\text {Thr }}$ A15951G $[28,29]$. These data suggested that these mtDNA haplogroup-specific variants may not play an important role in the phenotypic expression of the LHON-related mtDNA primary mutations in these pedigrees.

\section{Conclusions}

In summary, our study indicated that mitochondrial ND1 G3460A, ND4 G11778A and ND6 T14484C mutations were the molecular basis for LHON, screening for these primary mtDNA mutations were recommended for early detection and diagnosis of inherited optic neuropathy. The main limitation of this study was the relatively small sample size, further studies including more LHON patients were needed to be performed.

\section{Declarations}

\section{Acknowledgements}

Not applicable.

\section{Authors' contributions}

YJY and XMZ participated in the design of this study, FZ collected the samples and controls, YJY performed the genetic, molecular analysis and drafted the manuscript. All authors read and approved the final manuscript.

\section{Funding}

None.

\section{Availability of data and materials}

All data generated or analyzed during this study are included in this published article. 


\section{Ethics approval and consent to participate}

This work was approved by the Ethics Committee of Fuzhou Second Hospital, Xiamen University.

\section{Consent for publication}

Not applicable.

\section{References}

1. Rosenberg T, Nørby S, Schwartz M, Saillard J, Magalhães PJ, Leroy D, Kann EC, Duno M. Prevalence and genetics of Leber Hereditary Optic Neuropathy in the Danish population. Invest Ophthalmol Vis Sci. 2016;57(3):1370-1375.

2. Jia X, Li S, Xiao X, Guo X, Zhang Q. Molecular epidemiology of mtDNA mutations in 903 Chinese families suspected with Leber hereditary optic neuropathy. J Hum Genet. 2006;51(10):851-856.

3. Yu Wai Man P, Griffiths PG, Chinnery PF. Mitochondrial optic neuropathies disease mechanisms and therapeutic strategies. Prog Retin Eye Res. 2011;30(2):81-114.

4. Wallace DC, Singh G, Lott MT, Hodge JA, Schurr TG, Lezza AM, Elsas LJ 2nd, Nikoskelainen EK. Mitochondrial DNA mutation associated with Leber's hereditary optic neuropathy. Science. 1988; 242(4884):1427-1430.

5. Brandon MC, Lott MT, Nguyen KC, Spolim S, Navathe SB, Baldi P, Wallace DC. MITOMAP: a human mitochondrial genome database-2004 update. Nucleic Acids Res. 2005;33(Database issue): D611-613.

6. Catarino CB, Ahting U, Gusic M, luso A, Repp B, Peters K, Biskup S, von Livonius B, Prokisch H, Klopstock T. Characterization of a Leber's hereditary optic neuropathy LHON. family harboring two primary LHON mutations m.11778G >A and m.14484T>C of the mitochondrial DNA. Mitochondrion. 2017; 36:15-20.

7. Carelli V, La Morgia C. Clinical syndromes associated with mtDNA mutations: where we stand after 30 years. Essays Biochem. 2018; 62(3):235-254.

8. Yen MY, Wang AG, Wei YH. Leber's hereditary optic neuropathy: a multifactorial disease. Prog Retin Eye Res. 2006; 25(4):381-396.

9. Qu J, Zhou X, Zhao F, Liu X, Zhang M, Sun YH, Liang M, Yuan M, Liu Q, Tong Y, et al. Low penetrance of Leber's hereditary optic neuropathy in ten Han Chinese families carrying the ND6 T11484C mutation. Biochim Biophys Acta. 2010;1800(3):305-312.

10. Ding Y, Ye YF, Li MY, Xia BH, Leng JH. Mitochondrial tRNAAla 5601C>T variant may affect the clinical expression of the LHON-related ND4 11778G>A mutation in a family. Mol Med Rep. 2020;21(1):201-208.

11. Zhang S, Wang L, Hao Y, Wang P, Hao P, Yin K, Wang QK, Liu M. T14484C and T14502C in the mitochondrial ND6 gene are associated with Leber's hereditary optic neuropathy in a Chinese family. Mitochondrion. 2008;8(3):205-210.

12. Ji Y, Liang M, Zhang J, Zhang M, Zhu J, Meng X, Zhang S, Gao M, Zhao F, Wei QP, et al. Mitochondrial haplotypes may modulate the phenotypic manifestation of the LHON-associated ND1 G3460A mutation in Chinese families. J Hum Genet. 2014;59(3):134-140.

13. Andrews RM, Kubacka I, Chinnery PF, Lightowlers RN, Turnbull DM, Howell N. Reanalysis and revision of the Cambridge reference sequence for human mitochondrial DNA. Nat Genet. 1999;23(2):147.

14. Ji Y, Qiao L, Liang X, Zhu L, Gao Y, Zhang J, Jia Z, Wei QP, Liu X, Jiang P, et al. Leber's hereditary optic neuropathy is potentially associated with a novel m.5587T>C mutation in two pedigrees. Mol Med Rep. 2017;16(6):8997-9004.

15. Ding Y, Teng YS, Zhuo GC, Xia BH, Leng JH. The mitochondrial tRNAHis G12192A mutation may modulate the clinical expression of deafness-associated tRNAThr G15927A mutation in a Chinese pedigree. Curr Mol Med. 2019; 19(2):136-146.

16. Liang M, Jiang P, Li F, Zhang J, Ji Y, He Y, Xu M, Zhu J, Meng X, Zhao F, et al. Frequency and spectrum of mitochondrial ND6 mutations in 1218 Han Chinese subjects with Leber's hereditary optic neuropathy. Invest Ophthalmol Vis Sci. 2014; 55(3):1321-1331. 
17. Ruiz-Pesini E, Wallace DC. Evidence for adaptive selection acting on the tRNA and rRNA genes of human mitochondrial DNA. Hum Mutat. 2006; 27(11):1072-1081.

18. Kong QP, Bandelt HJ, Sun C, Yao YG, Salas A, Achilli A, Wang CY, Zhong L, Zhu CL, Wu SF, et al. Updating the East Asian mtDNA phylogeny: a prerequisite for the identification of pathogenic mutations. Hum Mol Genet. 2006;15(13):2076-2086.

19. Bibb MJ, Van Etten RA, Wright CT, Walberg MW, Clayton DA. Sequence and gene organization of mouse mitochondrial DNA. Cell. 1981; 26(2 Pt 2):167-180.

20. Gadaleta G, Pepe G, De Candia G, Quagliariello C, Sbisà E, Saccone C. The complete nucleotide sequence of the Rattus norvegicus mitochondrial genome: Cryptic signals revealed by comparative analysis between vertebrates. J Mol Evol. 1989;28(6):497-516.

21. Roe BA, Ma DP, Wilson RK, Wong JF. The complete nucleotide sequence of the Xenopus laevis mitochondrial genome. J Biol Chem. 1985; 260(17): 9759-9774.

22. Mackey DA, Oostra RJ, Rosenberg T, Nikoskelainen E, Bronte-Stewart J, Poulton J, Harding AE, Govan G, Bolhuis PA, Norby $\mathrm{S}$. Primary pathogenic mtDNA mutations in multigeneration pedigrees with Leber hereditary optic neuropathy. Am J Hum Genet. 1996;59(2):481-485.

23. Mashima Y, Yamada K, Wakakura M, Kigasawa K, Kudoh J, Shimizu N, Oguchi Y. Spectrum of pathogenic mitochondrial DNA mutations and clinical features in Japanese families with Leber's hereditary optic neuropathy. Curr Eye Res. 1998;17(4):403-408.

24. Romero P, Fernández V, Slabaugh M, Seleme N, Reyes N, Gallardo P, Herrera L, Peña L, Pezo P, Moraga M. Pan-American mDNA haplogroups in Chilean patients with Leber's hereditary optic neuropathy. Mol Vis. 2014; 20: 334-340.

25. Jiang P, Liang M, Zhang J, Gao Y, He Z, Yu H, Zhao F, Ji Y, Liu X, Zhang M, et al. Prevalence of mitochondrial ND4 mutations in 1281 Han Chinese subjects with Leber's Hereditary Optic Neuropathy. Invest Ophthalmol Vis Sci. 2015;56(8):4778-4788.

26. Kumar M, Kaur P, Kumar M, Saxena R, Sharma P, Dada R. Clinical characterization and mitochondrial DNA sequence variations in Leber hereditary optic neuropathy. Mol Vis. 2012; 18: 2687-2699.

27. Qu J, Zhou X, Zhang J, Zhao F, Sun YH, Tong Y, Wei QP, Cai W, Yang L, West CE, et al. Extremely low penetrance of Leber's hereditary optic neuropathy in 8 Han Chinese families carrying the ND4 G11778A mutation. Ophthalmology. 2009;116(3):558-564.

28. Qu J, Li R, Zhou X, Tong Y, Lu F, Qian Y, Hu Y, Mo JQ, West CE, Guan MX. The novel A4435G mutation in the mitochondrial tRNAMet may modulate the phenotypic expression of the LHON-associated ND4 G11778A mutation in a Chinese family. Invest Ophthalmol Vis Sci. 2006; 47(2):475-483.

29. Li R, Qu J, Zhou X, Tong Y, Hu Y, Qian Y, Lu F, Mo JQ, West CE, Guan MX. The mitochondrial tRNAThr A15951G mutation may influence the phenotypic expression of the LHON-associated ND4 G11778A mutation in a Chinese family. Gene. 2006; 376(1):79-86.

30. Caporali L, Maresca A, Capristo M, Del Dotto V, Tagliavini F, Valentino ML, La Morgia C, Carelli V. Incomplete penetrance in mitochondrial optic neuropathies. Mitochondrion. 2017; 36:130-137.

31. Khan NA, Govindaraj P, Soumittra N, Sharma S, Srilekha S, Ambika S, Vanniarajan A, Meena AK, Uppin MS, Sundaram C, et al. Leber's Hereditary Optic Neuropathy-specific mutation m.11778G>A exists on diverse mitochondrial haplogroups in India. Invest Ophthalmol Vis Sci. 2017;58(10):3923-3930.

32. Hudson G, Carelli V, Spruijt L, Gerards M, Mowbray C, Achilli A, Pyle A, Elson J, Howell N, La Morgia C, et al. Clinical expression of Leber hereditary optic neuropathy is affected by the mitochondrial DNA-haplogroup background. Am J Hum Genet. 2007;81(2):228-233.

33. Torroni A, Petrozzi M, D'Urbano L, Sellitto D, Zeviani M, Carrara F, Carducci C, Leuzzi V, Carelli V, Barboni P, et al. Haplotype and phylogenetic analyses suggest that one European-specific mtDNA background plays a role in the expression of Leber hereditary optic neuropathy by increasing the penetrance of the primary mutations 11778 and 14484. Am J Hum Genet. 1997;60(5):1107-1121.

Page $12 / 14$ 
34. Ji Y, Zhang AM, Jia X, Zhang YP, Xiao X, Li S, Guo X, Bandelt HJ, Zhang Q, Yao YG. Mitochondrial DNA haplogroups M7b1'2 and M8a affect clinical expression of leber hereditary optic neuropathy in Chinese families with the m.11778G->a mutation. Am J Hum Genet. 2008;83(6):760-768.

35. Zhang M, Zhou X, Li C, Zhao F, Zhang J, Yuan M, Sun YH, Wang J, Tong Y, Liang M, et al. Mitochondrial haplogroup M9a specific variant ND1 T3394C may have a modifying role in the phenotypic expression of the LHON-associated ND4 G11778A mutation. Mol Genet Metab. 2010; 101(2-3): 192-199.

\section{Figures}

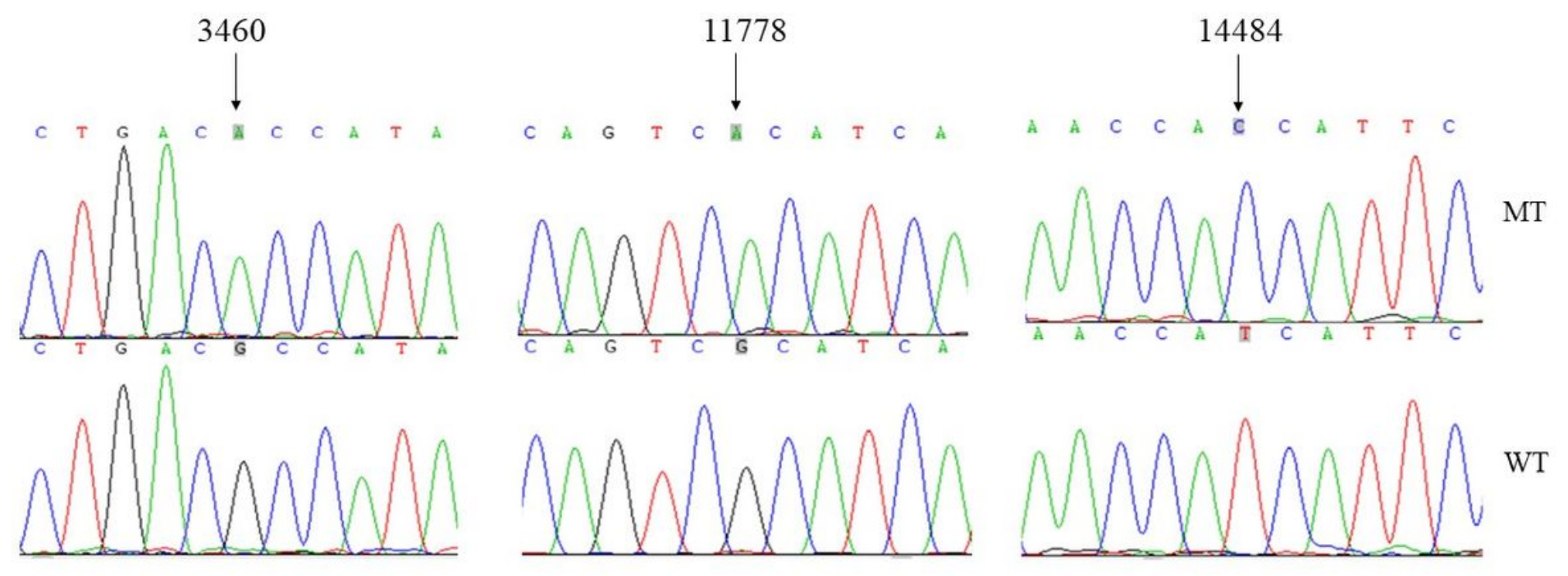

Figure 1

Identification of mitochondrial ND1 G3460A, ND4 G11778A and ND6 T14484C mutations by direct Sanger sequence. MT: mutant; WT: wild type. 

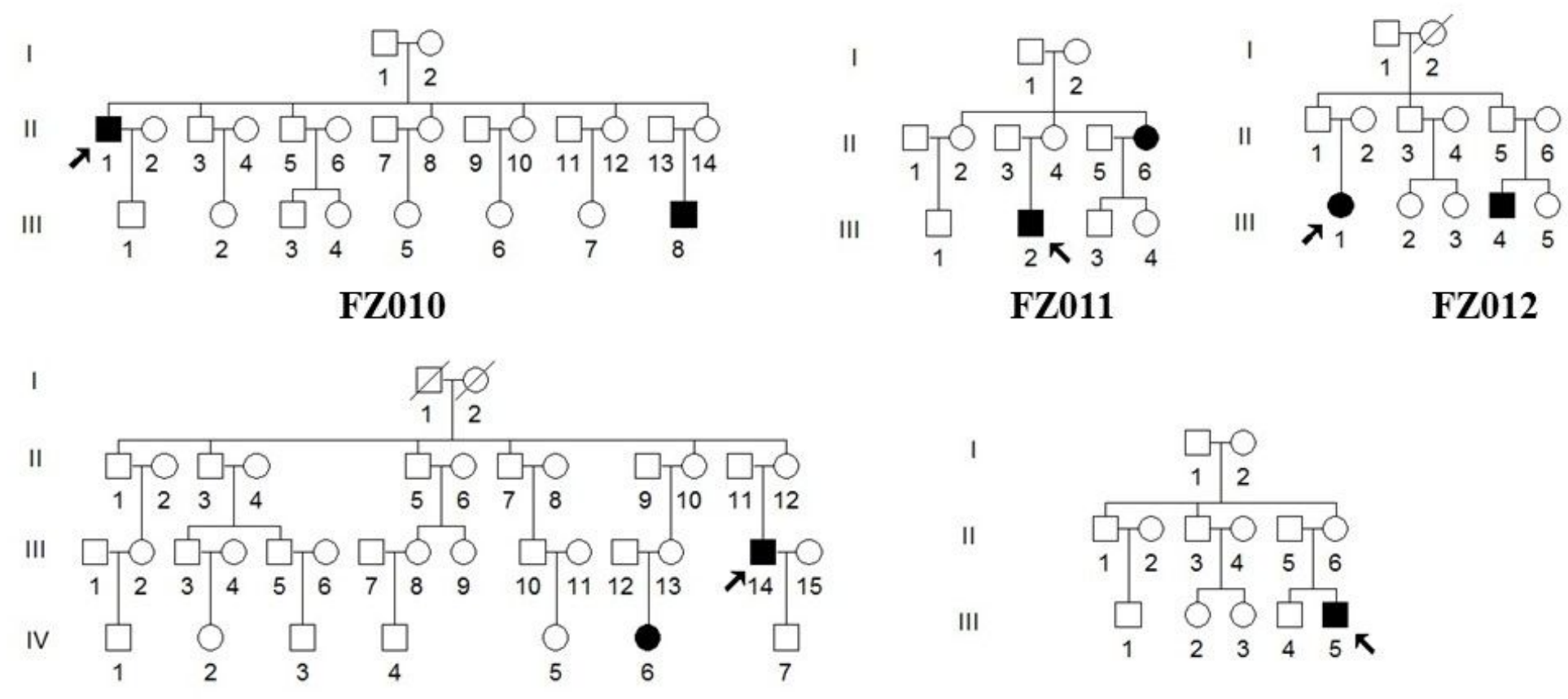

FZ013

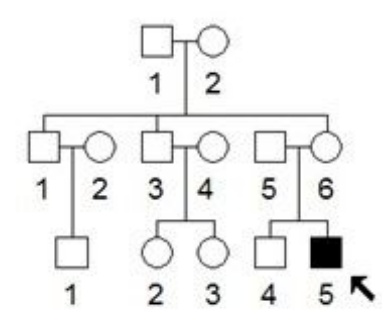

\section{FZ014}

\section{Figure 2}

Five Han Chinese pedigrees with LHON, arrows indicate the proband, the affected subjects are indicated by filled symbols. 